\title{
CORPO E PRÁTICAS DE CUIDADO DE SI: PROMOVENDO AÇÕES CLÍNICAS E PSICOEDUCATIVAS NA PREVENÇÃO AOS TRANSTORNOS ALIMENTARES
}

\author{
T. S. Queiroz 1' J. B. Dantas²; Y. F. S. Mota3; W.S. Simplício4; A.L.M. Matos5 \& A. A. Lobo6
}

${ }^{1}$ Bolsista e graduanda pela Universidade Federal do Ceará (UFC). E-mail: talitaqueiroz.esv@ @mail.com. ${ }^{2}$ Professora Adjunta do Departamento de Psicologia da Universidade Federal do Ceará. Coordenadora do Laboratório de Estudos em Psicoterapia, Fenomenologia e Sociedade (LAPFES/UFC). E-mail: juremadantas@ @ig.com.br; ${ }^{3}$ Bolsista e graduando em Psicologia pela Universidade Federal do Ceará. E-mail: yagofacanha@gmail.com; ${ }^{4}$ Graduando em Psicologia pela Universidade Federal do Ceará e extensionista do projeto. E-mail: wallisonsimplicio@gmail.com; ${ }^{5}$ Graduanda em Psicologia pela Faculdade Maurício de Nassau e extensionista do projeto. E-mail: lara.magas.m@gmail.com; ${ }^{6}$ Graduanda em Psicologia pelo Centro Universitário UniFanor Wyden e extensionista do projeto. E-mail: lobo.alineamori@gmail.com;

Artigo submetido em setembro/2018

\section{RESUMO}

O Projeto Corpore: por uma prática multiprofissional de prevenção aos transtornos alimentares, vinculado ao Laboratório de Estudos em Psicoterapia, Fenomenologia e Sociedade - LAPFES do Departamento de Psicologia da UFC tem como objetivo primordial oferecer um serviço multidisciplinar inovador e eficiente de prevenção aos transtornos alimentares. Suas ações aconteceram, inicialmente, na clínica escola de psicologia da UFC de julho de 2016 a junho de 2017, oferecendo atendimentos em grupo e individual, de cunho psicoterapêutico em caráter multiprofissional com profissionais colaboradores do projeto na área de nutrição. A partir do segundo semestre de 2017, suas atividades foram estendidas ao contexto escolar, pensando esse campo como possibilidade profícua para a problematização de questões relacionadas ao corpo e às possíveis distorções da autoimagem agregada às pesquisas realizadas pelo LAPFES desde 2016 até o presente momento em parceria com outros campos da conhecimento e instituições. Atualmente, no âmbito de suas ações de extensão, o projeto possui parceria com três escolas públicas de ensino médio de Fortaleza - CE, trabalhando em dois âmbitos de ação, o psicoeducativo e o psicoterapêutico. Com tais ações o projeto consolida sua relação com a comunidade e constrói novas possibilidades de promoção e prevenção em saúde junto ao público jovem, grupo que, segundo os dados quantitativos e qualitativos das pesquisas, apontam ter maior vulnerabilidade para o desenvolvimento de transtornos da autoimagem.

PALAVRAS-CHAVE: Autoimagem. Prevenção. Educação em Saúde. Contexto Escolar.

\section{BODY AND HEALTH CARE PRACTICES: PROMOTING CLINICAL AND PSYCHOEDUCTIVE ACTIONS IN THE PREVENTION OF FOOD DISORDERS}

\begin{abstract}
The Corpore Project: a multiprofessional practice in the prevention of eating disorders, linked to the Laboratory of Studies in Psychotherapy, Phenomenology and Society - LAPFES of the UFC Department of Psychology, has as its primary objective to offer an innovative and efficient multidisciplinary service to prevent eating disorders. His actions initially took place at the clinic psychology school of the UFC from July 2016 to June 2017, offering group and individual care, psychotherapeutic in a multiprofessional character with professionals of the project in the area of nutrition. From the second semester of 2017, its activities were extended to the school context, thinking this field as a useful
\end{abstract}

possibility for the problematization of issues related to the body and the possible distortions of the self-image added to the research carried out by LAPFES from 2016 until the present moment in partnership with other fields of knowledge and institutions. Currently, as part of its extension actions, the project has a partnership with three public high schools in Fortaleza - CE, working in two spheres of action, psychoeducational and psychotherapeutic. With these actions, the project consolidates its relationship with the community and builds new possibilities for health promotion and prevention among the young public, a group that, according to the quantitative and qualitative data of the researches, show a greater 
vulnerability to the development of self-image disorders.

KEYWORDS: Self image. Prevention. Health Education. School Context.

\section{INTRODUÇÃO}

O corpo suscitou curiosidade e interesse em diversas épocas e contextos da sociedade, porém a forma em que este se desenha atualmente é deveras peculiar. Dos corpos atléticos e vigorosos ostentados durante os jogos olímpicos na Grécia antiga, passando pela negação ferrenha de qualquer experiência corpórea "carnal" na idade média, até desembocar no grande palco de flashes e cliques no contemporâneo, o modo de vivenciar e compreender este mesmo corpo passou por muitas transformações. Na cultura contemporânea que, segundo Sibília (2008), passa por uma nova forma de subjetivação dos seus sujeitos, marcadamente a passagem de um eu introdirigido, voltado para si, para um eu alterdirigido, voltado para o exterior e esculpido ao bel prazer do olhar do outro, o corpo passa a receber fortes investidas quanto ao papel que deve desempenhar e passa a tornar-se um elegante cartão de visita. Nesse contexto, pode-se falar, inclusive, não mais em um culto ao corpo, mas sim culto à aparência. Trata-se, não mais, de cultivar o corpo em tentativa de alcançar o máximo de suas potencialidades, mas de extrair deste o que dele pode ser exibido. Nesse ponto um dos grandes paradoxos emerge de forma mais clara; em que estrutura tão fixa se sustenta o discurso do corpo magro como sinônimo do ser saudável? Ou ainda, de que forma se instituiu o corpo magro como belo e desejável? Nessa perspectiva, o corpo figura-se como campo fértil na construção de modos de subjetivação da chamada hipermodernidade (Lipovetsky, 2004). Discutir sobre as transfigurações que se estabelece perante os novos sentidos atribuídos à silhueta e as reverberações na vida dos sujeitos, mostra-se como um tema fundamental de problematização para o campo da psicologia.

Pensando sobre a problemática da supervalorização da aparência no contemporâneo e os possíveis atravessamentos no que diz respeito a enunciação do sofrimento relacionado à relação com o corpo, criou-se o "Projeto Corpore: por uma prática multiprofissional de prevenção aos transtornos alimentares”, projeto de extensão multidisciplinar do LAPFES Laboratório de Estudos em Psicoterapia, Fenomenologia e Sociedade, vinculado ao 
Departamento de Psicologia da Universidade Federal do Ceará - UFC, que iniciou suas atividades no primeiro semestre letivo de 2016 na Clínica Escola de Psicologia da UFC. O projeto possui como principal objetivo oferecer um serviço efetivo de prevenção aos transtornos alimentares junto à comunidade em geral. Suas ações surgiram como desdobramento da pesquisa desenvolvida pelo mesmo laboratório intitulada: "O corpo e seus dilemas: uma discussão sobre a construção da autoimagem na contemporaneidade", que ocorreu no período de 2015 até 2017, mas que, em função da temática e de seus desdobramentos, ainda se encontra com questões sendo pesquisadas em parcerias com o Departamento de Educação Física da UFC bem como com o Programa de Pós-Graduação em Transtornos Alimentares da UNIFOR. A pesquisa realizada durante esses dois anos supracitados direcionou suas discussões ao fenômeno do culto ao corpo ou corpolatria e suas implicações no processo de construção da autoimagem no contemporâneo. Tais discussões trouxeram à tona a consideração acerca do possível sofrimento relacionado à autoimagem, levando em conta o contexto atual de extrema preocupação com a aparência, o que fez surgir o interesse de trabalhar com pessoas que possuíssem algum tipo de insatisfação com a autoimagem.

Em agosto de 2016 o projeto começou suas atividades, inicialmente, na clínica escola de Psicologia da UFC, oferecendo atendimentos em grupo e individual realizados por estagiários e extensionistas vinculados ao LAPFES. Durante a experiência vivenciada com os atendimentos na Clínica escola, notou-se que o serviço foi mais procurado por jovens e adolescentes, pontuando a necessidade de ações direcionadas para esse público bem como os dados da pesquisa apontaram para prevalência de distorções de autoimagem no público jovem. Dessa forma, a partir de agosto de 2017, suas atividades foram estendidas ao contexto escolar, especialmente ao Ensino Médio. Atualmente o projeto possui parceria com três escolas públicas do ensino médio de Fortaleza e organiza suas ações em dois eixos: encontros quinzenais com a promoção de rodas de conversas e oficinas, de cunho psicoeducativo, e grupo psicoeducativo/psicoterapêutico em uma das escolas. Os membros do projeto fundamentam suas ações em uma perspectiva fenomenológico-existencial a partir da fenomenologia enquanto método e dos pressupostos teóricos fundamentados em conceitos apresentados por filósofos da existência como Jean-Paul Sartre e Martin Heidegger bem como realizam retomadas históricas sobre o estudo do corpo e seus enlaces e dilemas no contexto contemporâneo. Assim, todas as ações estão vocacionadas à uma reflexão sobre o papel do corpo na atualidade, as relações 
construídas no âmbito das noções de autoimagem e os desdobramentos possíveis de adoecimento psíquico.

Considerando que a insatisfação com a imagem corporal, segundo Andrade (2000), associada às práticas inadequadas de controle de peso e comportamento alimentar irregular, pode acarretar o que chamamos de transtornos do comportamento alimentar, este projeto de extensão pode se configurar como uma estratégia de prevenção aos transtornos alimentares. Ratificando, assim, a importância e a efetividade da psicoeducação enquanto instrumental da prática psicológica, em parceria com os atores presentes no contexto escolar.

\section{REFERENCIAL TEÓRICO}

O ideário de corpo foi e é bastante estudado por diversos autores, as reflexões e descobertas sobre esse tão emblemático objeto parece não se esgotar. Mas o que faz esta questão do corpo presente em todas as sociedades permanecer a despertar tanto interesse? Autores como Cassimiro, Galdino e Sá (2012) discutem sobre as dimensões que fazem parte da construção do sentido de corpo, assim como as transformações ocorridas nas várias concepções deste, explanando sobre este fenômeno. Os autores afirmam que o corpo se configura como um elemento de expressão cultural, assim, não é apenas matéria, de carne e osso, com contornos epidérmicos e funções fisiológicas, mas, sobretudo, onde se encarnam as experiências concernentes a um dado contexto. A relação homem e mundo é marcada justamente pela experiência corporal. O corpo então se traduz enquanto campo simbólico atravessado por aspectos culturais, políticos, sociais e econômicos.

Ao longo dos anos, o corpo foi pensado de diversas formas e várias discussões foram levantadas em torno dele. Contudo, no cenário contemporâneo, observa-se um destaque ainda maior a este corpo, sendo visto como um objeto de investimento e exibição que pode (deve) ser moldado e modificado com a mesma rapidez com que se consome qualquer produto do mercado. Sibilia (2004) nos aponta que o ideário promovido pela constante busca da beleza corporal cada vez mais proeminente implica, também na propagação dos cuidados do corpo como um dever moral que transborda até mesmo cuidados estéticos ou o discurso retórico envolvendo questões do bem-estar e da saúde. Trata-se de um dever que implica em possíveis sensações de impotência e negligência nas práticas de cuidado de si. Práticas que precisam ser a cada tempo reinventadas, repensadas, vigiadas e mantidas. Assim, enquanto aqueles que se 
aproximam do "corpo ideal” são considerados vitoriosos e dignos de aclamações, aqueles que não se encontram dentro do ideal esperado, são rejeitados.

Observamos na atualidade, uma cobrança cada vez maior para se alcançar o corpo ideal. Corpo esse, que não deve apenas ser magro e malhado, mas também jovem e produtivo. Inúmeros são os aparatos oferecidas ao sujeito para conquistar o corpo tão desejado. Tais como dietas, remédios, procedimentos estéticos entre outros. Na sociedade contemporânea, o modelo oferecido como corpo ideal parece se impor de maneira cada vez mais opressiva e generalizada, investindo os corpos e as subjetividades com uma potência inédita e promovendo novas formas de subjetivação e reinvenção da relação com o próprio corpo. Uma relação que, segundo Dantas (2011), ancorada na aparência e na apresentação, se traduz na vivência de um paradoxo intenso e perverso. Paradoxo marcado por um ideal sempre inatingível e por uma relação de eterno débito com este corpo, sobretudo, no contexto da lógica do capital onde cada vez mais o corpo se coloca no seio do mercado das aparências.

Podemos considerar que o "culto a aparência" se configura como uma forte característica da sociedade contemporânea, de forma que o "corpo ideal”, performático, exibível, seja visto como uma grande conquista, fonte de felicidade e conquista pessoal. Ao mesmo tempo em que os aparatos tecnológicos avançam e a mídia em geral apresenta infindáveis formas de se alcançar um ideal padronizado, o tal corpo ideal nunca será alcançado por todos. Assiste-se, assim, a perversidade travestida de democratização. Mattos (2014) afirma ainda que na atualidade o corpo foi espetacularizado e o discurso atual não fala de um corpo ou organismo, mas sobre a imagem, corroborando com Debord (1997) que ressalta o valor atribuído à aparência no contemporâneo.

Pode-se afirmar que a preocupação com corpo constitui um imperativo no contemporâneo. O culto à aparência, segundo Dantas (2014) se mostra como característica de nossa época, amparado pela crença exacerbada na biotecnologia e amplamente impelido pelos meios de comunicação. O aumento do vício pela perfeição anda lado a lado com o aumento da incidência do excesso de peso em todos os estratos etários e dos transtornos alimentares. No contemporâneo assistimos então de forma ampla e concreta o enunciar de muitos paradoxos.

Ao mesmo tempo em que se utiliza toda a organicidade desse corpo capturado pela biomedicina, nega-se totalmente essa característica humana na extrapolação de todos os seus limites e na negação de suas marcas. Nessa perspectiva, não é de se espantar que em uma sociedade que prega o gozo contínuo e exacerbado, assim como a felicidade instantânea repudie 
um corpo que é "encarnado" e que o destino natural seja o decaimento. Tal corpo é condenado justamente por ser finito e orgânico. A sociedade dos paradoxos procura homogeneizar as diferenças elegendo o corpo como meio profícuo para isso. Nesse meio caótico emergem as psicopatologias alimentares como reflexo do mal-estar contemporâneo. Tal cenário convoca os profissionais de saúde para uma ampliação do olhar, inclusive, integrando a construção da autoimagem como forma de promover uma atenção em saúde integral. O uso da psicoeducação, no caso deste projeto, configura-se como uma estratégia de ação frente ao objetivo central que é a prevenção dos transtornos alimentares. De acordo com Lemes e Neto (2017) a psicoeducação é uma técnica que fundamenta sua ação na psicologia e a pedagogia com o intuito de ensinar o sujeito sobre sua patologia, ou sobre sua condição de tratamento, como forma de auxiliar e tornar a intervenção mais eficiente. Assim, é possível oferecer um serviço de conscientização e prevenção em saúde.

A relação com o corpo é expressa de diversas formas. Uma delas é o comportamento alimentar, fortemente atravessado pela autoimagem que os sujeitos constroem de si. Tendo em vista que o objetivo é atuar com a prevenção dos transtornos alimentares, cabe destacar que diversos fatores influenciam no comportamento alimentar, tais como necessidades fisiológicas, hábitos familiares, contexto social e econômico, amigos, valores, modismos, saúde individual, mídia e experiências. A insatisfação com o próprio corpo, segundo Freitas e Freitas (2014), é um indicativo de alerta para o surgimento de transtornos alimentares, demonstrada de várias formas, seja de dietas irregulares, vergonha do próprio corpo ou exercícios exagerados. Levando em consideração a gravidade dessa condição, destacando que dentre os transtornos psiquiátricos os transtornos alimentares são os que mais levam a óbito, sustentamos a importância de construir estratégias multidisciplinares que problematizem a temática, principalmente com o público adolescente.

\section{MATERIAIS E MÉTODOS}

$\mathrm{Na}$ fase inicial do projeto, em 2016, antes dos atendimentos começarem a funcionar na clínica escola de Psicologia da UFC, realizou-se a divulgação do serviço através das redes sociais, panfleto e cartazes afixados em locais públicos e instituições de saúde pública com grande circulação de pessoas. Posteriormente, foram realizadas as inscrições via e-mail e os interessados foram contactados e convidados para uma entrevista de triagem realizada por 
estagiários com o apoio de extensionistas. Os interessados que atenderam ao perfil foram encaminhados ao atendimento em grupo com a colaboração mensal da presença de um profissional da nutrição em ações educativas e acompanhamento clínico.

A partir de julho de 2017 o projeto expandiu suas atividades ao contexto escolar. Realizou-se, então, visita a uma escola pública de ensino médio integral de Fortaleza, a saber a Joaquim Moreira de Sousa, para a apresentação da proposta de ação, em caráter piloto. A escolha da escola se deu por conta da aproximação já existente com a coordenação do local, a partir de outros projetos realizados pelo LAPFES. Após o contato inicial com a escola, a própria coordenação indicou qual turma participaria do projeto. Direcionados à turma em questão, no primeiro encontro, realizou-se o levantamento junto aos alunos de demandas e temas que deveriam compor o cronograma de atividades.

Tendo em vista a experiência com a escola dita anteriormente, decidiu-se organizar as atividades de forma a incluir escolas de ensino que não somente o integral e trabalhar com os âmbitos psicoeducativo e psicoterapêutico. Dessa forma, no início de 2018, o projeto começou a funcionar nesses dois eixos, realizando encontros quinzenais e grupo psicoeducativo/psicoterapêutico. Em fevereiro de 2018 foram realizadas visitas em várias escolas de Fortaleza para a apresentação do projeto e atualmente este mantém parceria com três escolas públicas: EEEP Joaquim Moreira de Sousa, EEM Adauto Bezerra e EEEP Juarez Távora. Nas escolas Joaquim Moreira de Sousa e Juarez Távora realizam-se os encontros quinzenais, seguindo a mesma metodologia da experiência piloto. Na escola Adauto Bezerra a proposta centrou-se na inserção de um grupo de compartilhamento de experiências e construções em conjunto com um caráter psicoeducativo/psicoterapêutico. Realizou-se, para tal, divulgação em todas as salas de primeiros e segundos anos do colégio, solicitando inscrições via e-mail e através de uma ficha deixada na biblioteca. Os interessados foram contactados e convidados para uma entrevista de triagem na própria escola em um sábado, dia mais adequado para a atividade por ser menos movimentado. As atividades do grupo ainda não iniciaram, porém, toda a logística e o planejamento já foram acordados com a instituição. O grupo terá frequência semanal e será facilitado por três terapeutas, extensionistas do laboratório, estudantes da UFC e de outras instituições de ensino superior, com duração de uma hora e meia. Os encontros ocorrerão em uma sala previamente reservada e que garanta sigilo para os participantes. Haverá um momento com os pais dos alunos encaminhados ao grupo, antes do 
início das atividades, para uma breve explicação sobre o projeto e para a assinatura do termo de ciência autorizando a participação do adolescente.

Nas outras duas escolas e como já informado anteriormente, os encontros acontecem de forma quinzenal com duração de 50 minutos na Joaquim Moreira e 1:40 na Juarez Távora. Lembrando que o tempo de duração acordado com a instituição depende da disponibilidade desta. $\mathrm{O}$ cronograma de atividades em ambas as escolas foi montado em parceria com os alunos das turmas indicadas, após levantamento de demandas e temas que mais despertava o interesse dos participantes. São convidados profissionais de várias áreas para participarem do projeto, como educadores físicos, nutricionistas e psicólogos para discutir temas pertinentes à temática em questão. Além de serem ofertadas várias oficinas pelos extensionistas com o intuito de suscitar a problematização de questões relacionadas ao corpo. Para as oficinas, utilizou-se como recursos áudios, vídeos, dinâmicas de grupo e materiais de pintura e recorte.

Em suma, as atividades do projeto "Corpore: por uma prática multiprofissional de prevenção aos transtornos alimentares" direcionado ao público escolar abrange a faixa etária de 14 a 18 anos, com turmas indicadas pela coordenação da instituição, ou por demanda espontânea no caso do grupo psicoeducativo. Especificamente no caso do grupo, o objetivo foi trabalhar com demandas envolvendo possíveis distorções da autoimagem, insatisfação com a imagem corporal e problemas de autoestima, porém sem transtornos alimentares já estabelecidos ou acompanhamento especializado já em curso em qualquer equipamento de saúde. Por meio de análise quantitativa, em função de adesão ao projeto e número de atendidos ao longo desses semestres, entendemos que o Corpore, em seus diferentes eixos e propostas de ação, vem se consolidando como prática efetiva de prevenção aos transtornos alimentares e, por fim, acreditamos que com a análise qualitativa dos dados, considerando as vivências dos participantes, os discursos expressos em entrevistas e os dados de pesquisa de satisfação, possamos ampliar, ao longo do próximo ano, nossas ações e consolidar um trabalho efetivo e multiprofissional voltado para novas práticas de cuidado de si.

\section{RESULTADOS E DISCUSSÕES}

O projeto Corpore vem construindo ao longo de seu percurso espaços de acolhimento e discussão para temáticas que evidenciam o sofrimento psíquico decorrente das imposições sociais que recaem sobre o corpo, desde o início de suas atividades na clínica de psicologia da 
UFC até os dias de hoje. Com a transição para o contexto escolar, o projeto se consolidou como uma forma de intervenção que se insere no cotidiano do público atendido, chegando até os atores sociais desejados nos seus respectivos espaços de construção de sentido, onde grande parte das relações interpessoais dos mesmos acontecem. Atuando numa perspectiva psicoeducativa, as intervenções ocorreram de maneira democrática, onde os estudantes participaram ativamente do processo, tanto no que diz respeito às oficinas desenvolvidas quanto nas palestras promovidas. As atividades realizadas pelo Corpore no âmbito escolar têm como principal objetivo trabalhar a questão da autoimagem e da relação estabelecida com o corpo promovendo uma possível estratégia de prevenção aos transtornos alimentares. Dessa forma, se configura, tacitamente, como uma possibilidade de ajuda aos casos de sofrimentos psíquicos relacionados à imagem corporal, que se mostram tão frequentes na sociedade contemporânea.

Como bem afirmam Olivera e Hutz (2010) os transtornos alimentares são multifatoriais e, por consequência, demandam atenção de profissionais distintos. Deste modo, vale ressaltar que, na tentativa de realizar intervenções mais eficientes, o projeto Corpore sempre recorreu a uma abordagem multiprofissional de atuação, convidando palestrantes das áreas de psicologia, educação física e nutrição, contribuindo com a construção de uma visão integrada das questões que rodeiam o corpo e a imagem corporal.

A preocupação exacerbada com a aparência e a busca frenética por artifícios que retardam e combatem o próprio corpo, marcas da contemporaneidade, possuem reverberações profundas nos modos de subjetivação atuais. Segundo Sibilia (2004), a sociedade contemporânea vivencia por um lado o culto à forma corporal e à ostentação estética, porém, por outro lado, tudo aquilo que é próprio do corpo, sua materialidade orgânica e seus traços históricos, é rejeitado através de práticas e procedimentos que intervém e prometem eliminar os riscos de uma aparência fora do padrão exigido. É dentro dessa perspectiva que as atividades do projeto Corpore se situam, promovendo discussões com os estudantes que evidenciam essas temáticas, na tentativa de gerar reflexões potencializadoras de mudanças positivas na relação com o corpo.

Entendendo os benefícios que a psicoeducação enquanto método interventivo pode acarretar nos processos de educação em saúde e a sua possível utilização no contexto escolar (LEMES; NETO, 2017), o projeto Corpore nas Escolas elegeu essa postura como método, pois assumiu-se que para se efetivar uma prática de prevenção aos transtornos alimentares é 
necessário atuar sobre o sofrimento psíquico gerado pelas exigências sociais que recaem sobre a imagem corporal, e dentro de uma postura psicoeducativa foi possível construir espaços de diálogo com os estudantes, onde eles puderam se colocar e criar novos significados coletivos.

O público alvo atendido pelo projeto, como já citado anteriormente, são adolescentes na faixa etária correspondente para se estar cursando o ensino médio. A eleição destes jovens como foco de atuação não se deu ao acaso. Pensando a partir das contribuições de Araújo (2016), a adolescência é um período de intensas transformações, transformações essas que perpassam não somente a dimensão biológica, mas principalmente a esfera social e psicológica do sujeito. É um período onde diversos fatores podem colaborar para experiências de insatisfação corporal, gerando sofrimento psíquico que, em última instância, é fator de risco para o desenvolvimento de transtornos alimentares. A escolha deste público enfatiza o compromisso social do projeto Corpore, se adaptando às demandas contemporâneas.

No que concerne a experiência vivida até o momento na escola de ensino médio Joaquim Moreira, pode-se constatar o interesse do público em participar do projeto. A turma acompanhada conta com a média de 40 estudantes, e salvaguardando as características específicas da mesma, foi possível perceber o movimento dos alunos de se posicionar quanto às temáticas e realizar as atividades propostas. Surgiram temas como corpo e mídia, corpo e sofrimento psíquico, corpo e sexualidade, bullying, dentre outros. Houve momentos de grande interação coletiva, como, por exemplo, durante uma das oficinas propostas pela equipe, na qual se almejava discutir a relação existente entre corpo e mídia. Os estudantes refletiram sobre as informações que circulam nos meios midiáticos, principalmente em revistas, direcionadas ao corpo, muitas vezes contendo discursos que não representam a grande maioria das pessoas. Ao final eles foram convidados a construírem suas próprias capas de revista, contendo aquilo que eles gostavam e que realmente lhes fizessem sentido. Houve a adesão e empenho de toda a turma durante a atividade.

Quanto a atuação na escola Juarez Távora, o processo também se deu de forma semelhante, embora fosse possível notar as particularidades da turma. As temáticas que eles optaram por trabalhar giraram em torno do corpo, autoimagem, mídia e sexualidade. Os estudantes participaram ativamente das discussões desde o primeiro encontro, expondo suas opiniões e colocando questões para se refletir coletivamente. As palestras promovidas, em particular a realizada por uma Educadora Física sobre saúde corporal, trouxeram contribuições pertinentes sobre a experiência de corpo no contemporâneo. 


\section{CONSIDERAÇÕES FINAIS}

Trabalhar com corpo e autoimagem, temas estes atravessados por questões de caráter socioculturais, econômicas e políticas, tendo em vista uma perspectiva de prevenção aos transtornos alimentares, mostra-se uma tarefa complexa e muito desafiadora. Levando em consideração que são desconhecidas outras iniciativas nesse formato. O projeto apresenta-se como pioneiro no estado do Ceará, que até então não conta com dispositivos ou projetos que atuem com o viés da prevenção. Por isso, a postura multidisciplinar do Corpore tem se mostrado a melhor forma de abraçar as pretensões do projeto. Entende-se que a psicologia deve colaborar com outras áreas de conhecimento, construindo um elo forte e integral. O projeto está em crescimento e favorece muitas parcerias, como a parceria acadêmica com o Prof. Dr. Ricardo Gonzalez, coordenador do programa de extensão universitária Esporte Educacional e Qualidade de Vida em Crianças e Adolescentes do Departamento de Educação Física da UFC. Tal parceria possibilita a troca de conhecimentos e oportunidades em pesquisa, aliando os três eixos que sustentam o saber científico; o ensino, a pesquisa e a extensão. O projeto conta, ainda, com um eixo de pesquisa sobre o corpo, coordenado pela Professora. Dra. Jurema Barros Dantas que conta com a colaboração com a Professora Ângela Andrade da UNIFOR em termos de interlocução e produção científica. Este eixo se apresenta como o momento em que os membros envolvidos podem discutir questões teóricas além de correlacionar a teoria com a prática, em um processo contínuo de aperfeiçoamento bem como se apresenta como um espaço aberto para supervisão das atividades psicoeducativas e psicoterapêuticas. Os encontros, que ocorrem semanalmente, também têm como intenção a possibilidade de participação de profissionais de outras áreas que possam compartilhar seus conhecimentos com o intuito de fomentar discussões que conduzam a um entendimento do corpo mais amplo e complexo.

Entendemos que o projeto com sua modalidade de atividade em grupo proporciona aos discentes e aos participantes uma experiência única de compartilhamento. Constitui-se também como objetivo do projeto promover a qualificação dos mesmos, além de fomentar novas formas de atuação no campo da psicologia, ciente das novas demandas do contemporâneo. A problematização sobre as questões do corpo e as reverberações da severidade em que este está submetido no contexto atual, abre o olhar para contemplar novas forma de enunciação do sofrimento humano. Conclui-se que o projeto Corpore atua na prevenção e promoção em saúde com o público jovem. Além disso, mantém de forma consistente parcerias com escolas, 
propiciando a discussão sobre saúde mental no contexto escolar, meio repleto de vicissitudes e que demanda um olhar atento diante da importância que a escola possui na construção identitária dos sujeitos. O projeto propicia, ainda, a aproximação da universidade com a comunidade, configurando a experiência de extensão e firmando o papel da universidade como agente de transformação social.

\section{REFERÊNCIAS}

ANDRADE, A. C. Para além dos sintomas: a trilogia do desamparo no vivido de mulheres com transtornos do comportamento alimentar. 2000. 250p. Dissertação (Mestrado em Saúde Pública) - Departamento de Saúde Comunitária da Faculdade de Medicina de Fortaleza, Universidade Federal do Ceará, Fortaleza, 2000.

ARAÚJO, E. C. Transtornos alimentares na adolescência. Revista de Enfermagem Ufpe, Recife, v. 10, n. 9, p.1-2, set. 2016. Disponível em: $<$ https://periodicos.ufpe.br/revistas/revistaenfermagem/article/download/11395/13158>. Acesso em: 02/09/2018.

CASSIMIRO, E. S.; GALDINO, F. F. S.; SÁ, G. M. As concepções de corpo construídas ao

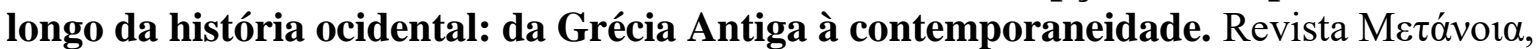
São João del Rei, n. 14, 2012.

DANTAS. J. B. Tecnificação da Vida: uma discussão sobre o fenômeno da medicalização na sociedade contemporânea. Curitiba, Editora CRV, 2014.

DANTAS, J. B. Um ensaio sobre o culto ao corpo na contemporaneidade. Estud. pesqui. psicol. [online]. 2011, vol.11, n.3, pp. 898-912. ISSN 1808-4281.

DEBORD, G. A sociedade do espetáculo: comentários sobre a sociedade do espetáculo. Rio de Janeiro: Contraponto, 1997.

FREITAS, S.; FREITAS, P. Imagem corporal nos transtornos alimentares e na obesidade. In: MATTOS, R. Imagem Corporal: Novos Olhares Numa Perspectiva Interdisciplinar Para o Século XXI. Rio de Janeiro: Paco Editorial, 2014.

LEMES, C.; NETO, J. Aplicações da Psicoeducação no Contexto da Saúde. Temas em Psicologia, Ribeirão Preto, v. 25, n.1, p. 17-18, mar. 2017. Disponível em: $<$ http://pepsic.bvsalud.org/scielo.php?script=sci_arttext\&pid=S1413-389X2017000100002>. Acesso em: 02/09/2018.

LIPOVETSKY, G. Os tempos hipermodernos. São Paulo: Editora Barcarolla, 2004.

MATTOS, R. Imagem Corporal: Novos Olhares Numa Perspectiva Interdisciplinar Para o Século XXI. Rio de Janeiro: Paco Editorial, 2014. 
OLIVEIRA, L. L.; HUTZ, C. S. Transtornos alimentares: o papel dos aspectos culturais no mundo contemporâneo. Psicologia em Estudo, Maringá, v. 15, n. 3, p. 575-582, jul./set. 2010. Disponível em: <http://www.scielo.br/pdf/pe/v15n3/v15n3a15>. Acesso em: 02/09/2018.

SIBILIA, P. Em busca da felicidade lipoaspirada: agruras da imperfeição carnal sob a moral da boa forma In: FREIRE FILHO, J. Ser feliz hoje: reflexões sobre o imperativo da felicidade. Rio de Janeiro: Editora FGV, 2010.

SIBILIA, P. O pavor da carne: riscos da pureza e do sacrifício no corpo-imagem contemporâneo. Revista FAMECOS, Porto Alegre, nº 25, dezembro 2004.

SIBILIA, P. Eu personagem e o pânico da solidão. In: O show do eu: A intimidade como espetáculo. Rio de Janeiro: Nova Fronteira, 2008. 